\title{
The Italian version of the Depressive Experiences Questionnaire: psychometric properties and validation in students, community, and clinical groups
}

\author{
Giorgio Falgares, ${ }^{1}$ Sandro De Santis, ${ }^{2}$ Salvatore Gullo, ${ }^{3}$ Danilo Carrozzino, ${ }^{4}$ Daniela Marchetti, ${ }^{4}$ Maria Cristina Verrocchio, \\ Gianluca Lo Coco, ${ }^{1}$ Daniel Kopala-Sibley, ${ }^{5}$ Osmano Oasi ${ }^{6}$ \\ ${ }^{1}$ Department of Psychological, Pedagogical and Educational Sciences, University of Palermo; ${ }^{2}$ Local Health Unit, Trento Province; \\ ${ }^{3}$ Faculty of Psychology, University N. Cusano of Rome; ${ }^{4}$ Department of Psychological, Health and Territorial Sciences, University \\ G. d'Annunzio of Chieti-Pescara, Italy; ${ }^{5}$ Department of Psychology, Stony Brook University, New York, NY, US; ${ }^{6}$ Department of \\ Psychology, Catholic University of Sacred Heart, Milan, Italy
}

\begin{abstract}
The current study evaluated the psychometric properties of the Italian validation of the Depressive Experiences Questionnaire (DEQ), conceived as a measure of self-criticism and dependency, i.e. two personality factors acting, according to Blatt (2004), as risk factors for depression in particular and psychopathology in general. A series of standardized measures [Beck Depression Inventory-II (BDI-II), DEQ, Symptom Checklist-90-R (SCL-90-R), Millon Clinical Multiaxial Inventory, 3rd edition (MCMI-III)] was administered to three samples (i.e., students, community and clinical). Factorial validity was evaluated along with convergent and predictive validity. In order to evaluate the reliability and internal consistency, a specific subgroup of participants was retested on the DEQ and BDI-II. Results showed correlations between DEQ dimensions and some personality traits of the MCMI-III. The traditional three-factor model of the DEQ structure as identified by principal component analysis appears to be as stable factors as typically found in American samples, although some items showed elevated cross-loading or low loadings on any factor. Clinical and diagnostic implications of the findings will be discussed.
\end{abstract}

Key words: Depressive Experiences Questionnaire; Italian validation; Personality.

Correspondence: Giorgio Falgares, Department of Psychological, Pedagogical and Educational Sciences, University of Palermo, viale delle Scienze 15, 90133 Palermo, Italy.

Tel: +39.091.23897715.

E-mail: giorgio.falgares@unipa.it

Contributions: all authors participated in the conceptualization and writing of this manuscript, and approved its final version.

Conflict of interest: the authors declare no potential conflict of interest.

Citation: Falgares, G., De Santis, S., Gullo, S., Carrozzino, D., Marchetti, D., Verrocchio, M.C., Lo Coco, G., Kopala-Sibley, D., \& Oasi, O. (2017). The Italian version of the Depressive Experiences Questionnaire: psychometric properties and validation in students, community, and clinical groups. Research in Psychotherapy: Psychopathology, Process and Outcome, 20(1), 81-90. doi: 10.4081/ripppo.2017.227

Received for publication: 12 December 2016.

Revision received: 4 March 2017.

Accepted for publication: 4 March 2017.

This work is licensed under a Creative Commons Attribution NonCommercial 4.0 License (CC BY-NC 4.0).

CCopyright G. Falgares et al., 2017

Licensee PAGEPress, Italy

Research in Psychotherapy:

Psychopathology, Process and Outcome 2017; 20:81-90

doi:10.4081/ripppo.2017.227

\section{Introduction}

In the early 1970s, Blatt and colleagues proposed a dynamic structural developmental approach that highlights a dimensional view of personality and its development, including both healthy and pathological dimensions (Blatt, D'Afflitti, \& Quinlan, 1976). According to Blatt (2004), personality proceeds through a dialectical and continuing interaction between the issues of identity, autonomy, and achievement on one hand, and interpersonal issues of relatedness, attachment, and intimacy on the other (Luyten \& Blatt, 2013).

In Blatt's theory (2008), mature personality can be considered a synergistic product of two main developmental configurations that extend throughout an entire lifetime: interpersonal relatedness, which involves developing the capacity for mature, intimate, reciprocal, and mutually satisfactory interpersonal relationships, and selfdefinition, which involves the development of a realistic, integrated, and differentiated identity or sense of self (Kopala-Sibley \& Zuroff, 2014).

According to Blatt (2004), even in normal development, individuals usually place an emphasis on one dimension, creating two basic personality styles. For some, the emphasis is on interpersonal relatedness and is more focused on the desire for harmonious, supportive, and re- 
ciprocal relationships. For others, there is an emphasis on self-definition, which is more focused on individuation, achievements, and identity formation (Blatt, 2004).

A severe disruption in this normal developmental dialectic process may result in a rigid, one-sided preoccupation with one of these two dimensions at the expense of the other. In particular, an overemphasis on issues of relatedness is the basis of a pathological personality style that Blatt labeled dependent/anaclitic. An overemphasis on issues of self-definition is the basis of a pathological personality style that he labeled self-critical/introjective (Blatt \& Blass, 1996).

According to Blatt, high levels of dependency and/or self-criticism confer vulnerability to stress and psychopathology, especially depression. Specifically, individuals with high dependency are preoccupied with interpersonal goals, and have an increased risk for developing depression due to interpersonal conflict, loss, or social rejection. On the other hand, individuals with high levels of self-criticism are preoccupied with achievement goals, and are especially susceptible to depression when they feel they are unable to meet high standards set by themselves and/or others (Blatt, 2008).

\section{The Depressive Experiences Questionnaire}

Based on a psychodynamic framework in which clinical depression is viewed as an extreme expression on a continuum with normal affective experiences, the Depressive Experiences Questionnaire (DEQ) is a self-report questionnaire that assesses two factors of depressive experiences, self-criticism and dependency. These factors are consistent with a formulation given by Blatt (1974) who proposed two primary sources of depression in adults; namely anaclitic and introjective dimensions of depression. More recently the DEQ was also used to assess personality trajectories focused on the development of interpersonal relatedness and self-definition throughout the life span (Blatt \& Blass, 1996; Campos, Besser, \& Blatt, 2013).

However, initially the DEQ was not constructed with the aim to measure these personality traits, but for investigating the general structure of depressive experiences (Desmet, Vanheule, Groenvynck, Verhaeghe, Vogel, \& Bogaerts, 2007). For this purpose, Blatt and colleagues (Blatt et al., 1976) reviewed the clinical literature on depression (Bibring, 1953; Cohen, Baker, Cohen, From-Reichman, \& Weigert, 1954; Jacobson, 1971) and formulated a list of 150 statements reflecting subjective experiences frequently reported by depressed patients. Subsequently, judges selected 66 items (positively and negatively worded) from this list, to represent the range of phenomenological experiences associated with depression (e.g., fear of loss, self-blame, distortions in family relations).

In order to explore psychometric properties of the DEQ, the measure was administered to 500 female and 160 male undergraduates who were asked to rate the 66 items on a 7-point scale from strongly disagree (1) to strongly agree (7). The instructions were: Listed below are a number of statements concerning personal characteristics and traits. Read each item and decide whether you agree or disagree and to what extent.

In both the female and male samples, a principal component analysis (PCA) with Varimax rotation revealed three orthogonal factors that explained $25 \%$ of the variance (see also Blatt, D'Afflitti, \& Quinlan, 1979). As reported by the authors To improve interpretation and comparison, the direction (positive and negative) and ordering (Factor 1, 2, and 3) of the three factors in males were aligned with the direction and order of the comparable factors in females (Blatt et al., 1976, p. 384). The items that had primary loadings on the first two factors reflected anaclitic and introjective orientations and were called dependency and self-criticism respectively. The third factor contained items that reflected a sense of trust in one's own resources and was labeled efficacy but has not generally been examined in the literature (Blatt et al., 1976). High levels of dependency involve excessive needs for close and dependent interpersonal relationships, fears of abandonment and object loss, and feelings of helplessness and loneliness (e.g.., Many times I feel helpless and I become frightened when I feel alone). Self-criticism reflects preoccupations with issues of failure, ambivalent feelings about self and others, and intense and harsh self-criticism (e.g.., I often feel guilty and I tend not to be satisfied with what I have). The efficacy factor reflects goal-oriented strivings, but not excessive competition with others (e.g.., I often feel what I have to say is important).

Blatt and colleagues (1976) tested the stability of the DEQ factor structure by means of a split-half procedure, and obtained a high degree of factor similarity (coefficients of congruence higher than .90) for each of the factors with their split-half duplicates. Blatt and colleagues (1976) constructed a complex scoring procedure to select items. Specifically, they developed a scoring program that uses means, standard deviations, and factor score coefficients of their student sample to compute standardized factor scores. It preserved all 66 items, including several items without high loadings on any of the factors (26 items in the female and 26 in the male sample without loadings $>.40$ ), and items with high loadings on more than 1 factor ( 2 in the female and 3 in the male sample with 2 loadings $>.40$ ). The advantage of this scoring program is that it results in a more subtle measurement by preserving the unique contribution of each of the items to each of the DEQ factors and produces orthogonal factors (Desmet, Vanheule, Groenvynck, Verhaeghe, Vogel, \& Bogaerts, 2007).

Despite its name, the DEQ is not a measure of depression, although it was originally conceptualized as such (Blatt et al., 1976). However, subsequent research (Zuroff, Mongrain, \& Santor, 2004; Mongrain \& Zuroff, 1994) showed that the DEQ measures stable personality traits which confer risk for the development of depression, but which do not measure acute depression. This proposal is in agreement with other dimensional tools (e.g., Psychodynamic Diag- 
nostic Manual Task Force, 2006), as opposed to instruments that assess the presence/absence of symptoms, because it assesses the psychological functioning of an individual rather than a clear-cut polarization (Blatt, 2008).

Subsequently, Blatt, Zohar, Quinlan, Zuroff, and Mongrain (1995) analyzed the construct of dependency by identifying two facets. The first facet, dependence, involves a more immature tendency, including feelings of helplessness, fears, and apprehensions about separation and rejection. The second facet, relatedness, is characterized as a more mature tendency and includes items that consider feelings of loss and loneliness in reaction to the disruption of a relationship with a particular individual.

Numerous empirical studies have supported the psychometric properties of the DEQ (e.g., Besser, Guez, \& Priel, 2008; Besser \& Priel, 2003, 2005; Besser, Priel, Flett, \& Wiznitzer, 2007; Besser, Vliegen, Luyten, \& Blatt, 2008; Campos et al., 2013; Franche \& Dobson, 1992; Nietzel \& Harris, 1990; Ouimette \& Klein, 1993; Yao, Fang, Zhu, \& Zuroff, 2009; Zuroff, Mongrain, \& Santor, 2004), including its internal consistency, test-retest stability, and predictive validity.

Research findings have also provided evidence of its usefulness with diverse population (see reviews in Blatt, 2004; Desmet et al., 2007, 2009), from students to clinical samples in different languages and cultures (e.g., Campos et al., 2013; Kuwabara, Sakado, Sakado, Sato, \& Someya, 2004).

Nevertheless, some investigators have questioned its validity (e.g., Coyne, Thompson, \& Whiffen, 2004; Coyne \& Whiffen, 1995; Desmet, Vanheule, \& Verhaeghe, 2006; Lehman et al., 1997; Viglione, Clemmey, \& Camenzuli, 1990). First, the relative predictive utility of self-criticism versus dependency remains unclear. Results have been mixed concerning whether dependency relates to depressive symptoms in clinical groups, over and above the effects of self-criticism (e.g., Priel \& Besser, 1999). Luyten et al. (2007), for example, reported a stronger effect of self-criticism on depressive symptoms compared to dependency in a college student group. However, Yao et al. (2009) found that depressive symptoms, as measured by the Center for Epidemiologic Studies-Depression Scale (CES-D), correlated more with dependency $(r=.59)$ than self-criticism $(r=.26)$. Several other studies have provided conflicting results (see Bagby, Parker, Joffe, \& Buis, 1994; Santor, Zuroff, \& Fielding, 1997; Viglione, Lovette, Gottlieb, \& Friedberg, 1995; Welkowitz, Lish, \& Bond, 1985; Zuroff, Quinlan, \& Blatt, 1990). Campos et al. (2013) found that both dependency and self-criticism were vulnerability factors to distress (hostility, anxiety, depression and interpersonal sensitivity), which could, in turn, result in an increased vulnerability for suicidality (see also Beck, 1983; Blatt, 1995; Fazaa \& Page, 2003). In contrast, Kopala-Sibley, Zuroff, Hankin, and Abela (2015) found that increases over time in self-criticism, but not dependency, longitudinally predicted increases in depressive symptoms.
Second, many authors have denied the orthogonality between dependency and self-criticism, suggesting overlap rather than independence of the two factors (Desmet et al., 2007; Fuhr \& Shean, 1992; Viglione et al., 1995; Welkowitz et al., 1985). In particular, authors have argued that Blatt's scoring procedure is used to confirm the orthogonality of the two factors and to produce intercorrelation coefficients that are artificially small.

Welkowitz et al. (1985), for example, developed a unit-weighted version, called the Revised Depressive Experiences Questionnaire (RevDEQ). The RevDEQ was constructed by selecting 43 items from the 66 items of the original DEQ (i.e., 20 for dependency, 15 for self-criticism, 8 for efficacy). This resulted in a high correlation between self-criticism and dependency $(r=.60)$ (Welkowitz et al., 1985). Bagby et al. (1994) also attempted to derive a shortened, unit-weighted revision, named the Reconstructed Depressive Experiences Questionnaire, by selecting 19 items (i.e., 10 dependency, 9 self-criticism) from the original scale. Again, however, orthogonality did not emerge between the dependency and self-criticism scales ( $r=.61$ in a depressed sample).

Viglione et al. (1995) constructed the Theoretical Depressive Experiences Questionnaire-21 (TDEQ-21) by selecting 21 items from the Original DEQ (i.e., 10 dependency and 11 self-criticism items) based on Blatt's theories. The analysis showed that of these 21 items, only 12 loaded satisfactorily (>.40), including 5 items for dependency and 7 for self-criticism. For this reason, this new version was labeled TDEQ-12 (Viglione et al., 1995). The results called the capacity of the items to thoroughly account for the related factors into question. In particular, the scale failed to emphasize the dimensions of guilt and turning upon the self within the introjective items, both of which characterize high levels of self-criticism as described by Blatt's theory (2004).

Although previous studies found highly correlated factors, other research found the two factors to be uncorrelated. For example, Santor, Zuroff, and Fielding (1997) and Santor, Zuroff, Mongrain, and Fielding (1997) presented a short version of the DEQ (McGill-DEQ) using a unit-weighted measure of dependency and self-criticism, which supported the orthogonality of both subscales. Using a heterogeneous clinical group and a college student group, the authors identified 12 communal items, which provided a sufficient degree of orthogonality. They found that at least 30 items are necessary to reach acceptable psychometric properties of the scale, especially in terms of orthogonality; however, when increasing the number of items beyond this threshold, there is no significant improvement in the scale's performance.

Others have further highlighted concerns that dependency and self-criticism are far from independent. Fuhr and Shean (1992), for instance, argued that the presence of mixed configurations (e.g., high dependency and high selfcriticism) is much more frequent than it appears in the re- 
search presented by Blatt and colleagues. Based on the great amount of research conducted within the framework of two basic dimensions of interpersonal relatedness and self-definition in personality and psychopathology (Blatt, 2008), especially depression, several efforts were undertaken to translate the DEQ into several languages including French, German, Hebrew, Spanish, Russian, Sweden, Croatian, Arabic, and, recently, Japanese and Chinese.

Kuwabara, Sakado, Sakado, Sato, and Someya (2004), for example, found that the Japanese version of the DEQ had reliability values similar to those obtained with the original DEQ. Comparing subjects with and without lifetime histories of major depression, they found that subjects with a history of depression had significantly higher scores on self-criticism, concluding that the Japanese DEQ assesses a depression-prone personality.

Boucher, Cyr, and Fortin (2006), using a French-Canadian version of the Depressive Experiences Questionnaire, found a very high degree of conformity with the original version in terms of the number of factors, variance explained and the pattern of factor loadings for each scale. Congruence of factor scores calculated with the solutions derived from the English and French principal component analysis was very high, but somewhat lower for the Selfcritical dimension for male subjects. The French-Canadian version of the Depressive Experiences Questionnaire correlated with a measure of depression, and showed adequate test-retest reliability over an 8-week period.

Yao et al. (2009), using the Chinese version of the DEQ, found that dependency and self-criticism predicted depression over a one month period in a non-clinical group, concluding that the Chinese version of the DEQ had satisfactory construct and predictive validity, and was appropriate for assessing vulnerability to depression in Chinese college students.

Campos et al. (2013) developed the Portuguese version of the DEQ and demonstrated acceptable psychometric properties (reliability and validity) in six samples (i.e., a bilingual sample, two college student groups, two community samples, and a clinical group). Results also indicate acceptable levels of test-retest reliability for the three DEQ factors. That is, the three DEQ factors measure stable personality characteristics that predict depressive symptoms over a six-month period.

Based on this background, the general aim of our research study is to further examine the psychometric properties of the DEQ by contributing to the Italian validation of this self-rating scale when specifically testing its convergent, discriminant, criterion, and predictive validity.

\section{Materials and Methods}

\section{Participants}

Participants were 431 individuals recruited in Italy. Of these, $2(.005 \%)$ respondents were excluded because they did not complete the full questionnaires. Missing data for one or more variables were replaced with the mean score of the scale where they did not exceed $20 \%$; if missing data exceeded this aforementioned cut-off, they were not used for statistical analyses. The effective sample consisted of 429 participants divided into three groups. The student group consisted of 133 subjects with a mean age of $21.18(\mathrm{SD}=2.89), 84 \%$ were females $(\mathrm{n}=112), 90 \%$ were unmarried. Three (less than 1\%) had a previous hospitalization for psychological reasons.

The clinical group consisted of 56 subjects with a mean age of $35.18(\mathrm{SD}=12.58) .70 \%$ were females $(n=40), 43 \%$ were unmarried $(n=40), 37 \%(n=21)$ married or cohabitating, $40 \%(\mathrm{n}=23)$ had a high school degree, $79 \%(n=39)$ were employed. $9 \%(n=5)$ had a previous hospitalization for psychological reasons.

The community sample consisted of 240 subjects with a mean age of $51.68(\mathrm{SD}=16.57)$. Sixty per cent were females ( $\mathrm{n}=144), 60 \%$ were married $(\mathrm{n}=143), 38 \%(\mathrm{n}=91)$ had a high school degree, and $78 \%(\mathrm{n}=186)$ were employed. Three per cent $(n=7)$ had a previous hospitalization for psychological reasons

\section{Procedure}

The protocol was developed according to the ethical guidelines of the Italian Association of Psychology (AIP).

Data collection was carried out from January 2015 to June 2016. Participants were recruited by research groups from three Italian universities (Palermo, Chieti, Milan; in the Southern, Central, and Northern Italy, respectively) contributing to enroll respondents from community, university, and clinical settings. For the community sample, trained research team members were sent to a variety of employment, recreational and university settings in the three Italian cities. Each member was asked to recruit an equal number of men and women, and participants who represent a range of age groups. For the student sample the head of each research team recruited a number of psychology students. When recruiting the community and student samples the only inclusion criterion was a lack of a medical history of psychiatric disorders. All individuals approached for participation were asked for their willingness to take part in a research study related to personality. Both for community and student samples those people who were interested in participation were informed of the voluntary nature of their involvement and right to withdraw at any time. All participants received and signed a written informed consent. Individuals who provided consent were escorted to a private area where they could sit and complete the questionnaire packet anonymously. After completing the initial questionnaire packet, participants were asked if they would be willing to participate in a brief follow-up study during a period ranging from three to four weeks. Those interested provided the researcher with contact information. At the follow-up appointment only the DEQ Italian version was completed. 
Concerning the clinical sample, participants were recruited at private and public outpatient services located in the three aforementioned Italian cities. To be eligible for inclusion in the clinical sample participants had to be under treatment with a defined diagnosis of a psychiatric disorder excluding dementia or other conditions that would invalidate their response to measures (e.g., anxiety, depression). To ensure confidentiality, treatment service staff conducted the recruitment of participants. Patients at these centers were made aware of the possibility of joining a research project about personality. Those volunteering were provided with a consent form and those who consented were asked to complete a questionnaire packet.

\section{Measures}

\section{Demographics questionnaire}

Demographic information included gender, age, education, occupation, marital status, and income.

\section{Depressive Experiences Questionnaire}

The Depressive Experiences Questionnaire (DEQ, Blatt et al., 1976) is a 66-item self-report questionnaire in which items are scored on a 7-point Likert scale, ranging from 1 (strongly disagree) to 7 (strongly agree). The DEQ scoring program yields scores on three scales: dependency, self-criticism, and efficacy.

The Italian version of the DEQ was developed using the back-translation method (Brislin, 1970). This procedure has been recommended by Kinzie and Manson (1987) for use in cross-cultural studies to ensure semantic integrity between versions of the measure. First, a bilingual translator from the Department of Psychology translated the instructions and items from the original version into Italian. Next, the Italian version was back-translated into English by another bilingual translator from the Department of Economics to confirm whether the translation matched the wording of the original scale. Finally, the original version was compared with the back-translated version. When discrepancies occurred between the two versions, the translators held discussions and worked cooperatively to make corrections to the Italian version. No items were eliminated or significantly adjusted during the translation process (Van de Vijver \& Hambleton, 1996), because only minor word changes were required to ensure semantic integrity.

\section{Beck Depression Inventory-II}

The Beck Depression Inventory-II (BDI-II, Beck, Steer, \& Brown, 1996) is a 21-item self-report questionnaire that measures the severity of depressed moods. For each symptom, statements are listed in ascending order from 0 (nondepressed) to 3 (severely depressed). For this study we considered only the overall score obtained by the sum of all items. Scores range from 0 to 63 , with each item indicating five levels (from mild to extreme) of depression. The psychometric properties of the Italian translation are acceptable and comparable to those of the original BDI-II (Ghisi, Flebus, Montano, Sanavio, \& Sica, 2006). In our study, the Cronbach's alphas were .76 for the students, .72 for community and .77 for the clinical group.

\section{Symptom Check List-90-R}

Symptoms were assessed by the Italian version of the Symptom Check List-90-R (SCL-90-R; Derogatis, 1994; Prunas, Sarno, Preti, Madeddu, \& Perugini, 2012). The SCL-90-R is a self-rating scale that gives a standardized measure of the current psychological and/or psychopathological status of a subject; this measure can be easily applied in non-clinical or psychiatric adult or adolescent populations. The scale provides a wide range of information on the current subjective experience of psychological distress, and potentially serves as a screening tool in both clinical and research settings. The severity of 90 symptoms during the last week is rated on a 5-point Likert scale, ranging from 0 (not at all) to 4 (extremely). The mean score of all 90 items, the global severity (or symptom) index (GSI), is considered the best single indicator of the current depth of disturbance (greater score greater severity). The other scores obtained are interpreted based on nine primary dimensions as follows: i) somatization; ii) obsessive-compulsive behavior; iii) interpersonal sensitivity; iv) depression; v) anxiety; vi) hostility; vii) phobic anxiety; viii) paranoid ideation; and ix) psychoticism.

\section{Millon Clinical Multiaxial Inventory-III}

Personality disorder traits were assessed with the Italian version of the Millon Clinical Multiaxial InventoryIII (MCMI-III; Millon, Millon, Davis, \& Grossman, 2006; Zennaro et al., 2013). The MCMI-III is a 175-item True/False questionnaire that provides individual profiles on 14 personality patterns and 10 clinical disorders according to Millon's personality theory (Millon et al., 2006). Items were designed according to diagnostic criteria listed in the DSM-IV-TR (APA, 2000). Given the purpose of the present study, only the scores of the following PDs were included in the analyses: depressive, masochistic, passive-aggressive, and sadistic PD. Raw scores are converted to Base-Rate (BR) scores, and a BR of 75 or greater is indicative of a significant clinical problem (Millon et al., 2006). The Italian version of the MCMI-III showed good overall reliability, with Cronbach's alphas ranging from .69 to .83 .

\section{Data analysis}

The factor structure of the Italian version of the DEQ was evaluated using Principal Component Analysis (PCA). Both oblique and orthogonal rotation were tested. Convergent validity was tested by conducting Pearson correlations between DEQ factors with the BDI-II, SCL90 and the MCMI-III scales, and internal consistency was 
tested with Cronbach's alpha. Pearson correlation coefficients were computed to examine how the DEQ Italian version performed across two administrations. Gender differences and comparisons among the three samples were examined via t-tests and ANOVAs.

\section{Results}

\section{Preliminary analyses}

In order to study the psychometric properties of the Italian version of the DEQ, a set of preliminary analyses were conducted. Data were examined for outliers and normal distribution of study variables. Logarithmic transformation was applied for not normally distributed variables, as follows: for SCL, GSI, PSDI, Somatization, ObsessiveCompulsive, Interpersonal Sensitivity, Depression, Anxiety, Phobic Anxiety, Paranoid Ideation, and Psychoticism scales; for MCMI-III, Depressive, Dependent, Masochistic, Self-Defeating, Schizotypal, Borderline, Somatoform, Alcohol Dependence, Drug Dependence, Post-Traumatic Stress Disorder, Delusional Disorder, and Major Depression scales.

\section{Factor structure}

Following Blatt et al. (1976), Zuroff et al. (1990), and Campos et al. (2013), PCA was first conducted on the student group. In the student group Scree Plot Test revealed that the three factor solution was the best fit to the data. PCA was initially followed by an oblique (oblimin) rotation. However, since the resulting correlation matrix for the factors show that none of the correlations (highest value of .16) exceeds the Tabachnick and Fiddell (2007) threshold of .32 we further used an orthogonal (Varimax) trasformation. After Varimax rotation, the first factor had an eigenvalue of 9.61, explaining $14.6 \%$ of the variance, the second had an Eigenvalue of 5.43 and accounted for $8.2 \%$ of the variance, and the third of 5.04, explaining $7.6 \%$ of the variance. Taken together the three factors accounted for $30.4 \%$ of the total variance. Furthermore, the PCA of the residuals did not yield additional factors with eigenvalues exceeding 3 , since the second ranged between 2.56 and 1.04 . The distribution of items with factor loadings greater than .40 on the three factors was quite different from that reported previously by Campos et al. (2013): 15 items (23\%) of the DEQ had no substantial loadings $(<.40)$ and 6 items $(9 \%)$ had high loadings on more than one factor (Appendix). The same PCA with Varimax rotation was repeated with the community sample showing similar results yielding three major factors that accounted for $11.53,6.49$, and $5.24 \%$ of total variance, respectively.

\section{Convergent validity, consistency and reliability}

Cronbach's alpha coefficient was calculated for each factor. For the overall sample, Cronbach's alphas were $.71, .65$ and .80 for dependency, self-criticism and efficacy, respectively. Dependency showed sufficient reliability for both males and females, as alphas were .66 and .75 , respectively. Cronbach's alphas for self-criticism and efficacy were the same between male and female subjects, with coefficients of .65 and .80 , respectively. Regarding differences among the three groups, alpha coefficient for dependency was .82 in the student group, .66 in the clinical group and .70 in the community sample. For self-criticism alphas were .74 in both the student and clinical groups, and .59 in the community sample. For efficacy, alphas were $.85, .78$ and .75 , respectively.

Convergent validity was tested by correlating subscales from the DEQ with those from the MCMI-III, SCL-90-R and BDI-II. Results are shown in Table 1. Dependency was significantly and positively correlated with BDI-II scores in both clinical and community samples $(r=.28, \mathrm{P}<.05$ and $r=.17, \mathrm{P}<.01$, respectively), although not in the student sample $(r=.08, \mathrm{P}=.37)$.

Table 1. Summary of Pearson's correlations for students, clinical, and community samples.

\begin{tabular}{|c|c|c|c|c|c|c|c|c|c|c|}
\hline & & \multirow[t]{2}{*}{ BDI } & \multicolumn{3}{|c|}{ MCMI-III } & \multicolumn{4}{|c|}{ SCL-90 } & \multirow[b]{2}{*}{ GSI } \\
\hline & & & Depression & Masochism & Somatization & Depression & $\begin{array}{c}\text { Interpersonal } \\
\text { sensitivity }\end{array}$ & Somatization & Anxiety & \\
\hline \multirow[t]{3}{*}{ Students } & Dependency & .08 & .06 & .09 & .06 & .04 & .10 & $.21 *$ & .05 & .09 \\
\hline & Self-criticism & $.67 * *$ & $.66^{* *}$ & $.53 * *$ & $.49 * *$ & $.49 * *$ & $.59 * *$ & $.37 * *$ & $.55 * *$ & $.68 * *$ \\
\hline & Efficacy & -.02 & -.14 & -.16 & -.02 & -.07 & .02 & .10 & -.00 & .03 \\
\hline \multirow[t]{3}{*}{ Clinical } & Dependency & $.28 *$ & $.24 *$ & .10 & $.34 *$ & $.32 *$ & .29 & .25 & .25 & $.37 * *$ \\
\hline & Self-criticism & $.51 * *$ & $.45^{* *}$ & $.41 * *$ & $.64 * *$ & $.59 * *$ & $.63^{* *}$ & $.41 * *$ & $.57 * *$ & $.63 * *$ \\
\hline & Efficacy & .08 & .16 & -.015 & .18 & .17 & .11 & .10 & .01 & .08 \\
\hline \multirow[t]{3}{*}{ Community } & Dependency & $.17 * *$ & $.19^{*}$ & $.16^{*}$ & $.27 * *$ & $.23 * *$ & .14 & .13 & .10 & $.22 * *$ \\
\hline & Self-criticism & $.52 * *$ & $.56 * *$ & $.37 * *$ & $.40 * *$ & $.38 * *$ & $.52 * *$ & $.45^{* *}$ & $.49 * *$ & $.56^{* *}$ \\
\hline & Efficacy & $.02 * *$ & .01 & .05 & .05 & .02 & -.09 & .03 & -.01 & -.01 \\
\hline
\end{tabular}

MCMI-III, Millon Clinical Multiaxial Inventory, $3^{\text {rd }}$ edition; SCL-90, Symptom Checklist-90-R; BDI, Beck Depression Inventory; GSI, global severity index. *P<.05; **P<.01. 
Moreover, dependency was significantly associated with the Depression scale of the SCL-90-R in both the clinical and community samples $(r=.32, \mathrm{P}<.05$ and $r=.23, \mathrm{P}<.05$, respectively), although also not in the student sample $(r=.04, \mathrm{P}=.63)$. Similar results were found regarding the correlation between dependency and the Depression scale of the MCMI-III, with significant associations obtained in both clinical $(r=.24, \mathrm{P}<.05)$ and community samples $(r=.19, \mathrm{P}<.05)$, but not in the student sample $(r=.06, \mathrm{P}=.88)$. However, it is important to highlight that many of these correlations were below the critical value of .30 .

Self-criticism correlated significantly with both BDIII and Depression scale of the SCL-90-R in all three samples. Pearson's coefficients between the self-criticism scale and BDI-II were $.68, .51$ and .52 (all $p_{s}<.01$ ) respectively for student, clinical and community samples (Figure 1), whereas correlations between the self-criticism scale and the Depression scale of the SCL-90-R were $.49, .59$ and .38 for student, clinical and community samples respectively (all $p_{s}<.01$ ). Similar correlations were obtained with the Depression scale of the MCMI-III (all ps <.01) in all the three samples ( $r=.66, r=.45$, and $r=.56$, respectively). All correlations between self-criticism and depression scales were above .30 . Efficacy was not significantly related to any measure of depressive symptoms in any sample ( $r$ ranged from .01 to .17 , all $p_{s}<.05$ ). External validity was also studied by conducting correlations with other measures of interpersonal sensitivity such as masochism, anxiety, somatization and the global severity index. Data are shown in Table 2.

Test-retest stability was examined via correlations between the two time points for each factor of DEQ. Regarding dependency, results showed that scores at the first time point were associated with score three weeks later in both student $(r=.61, \mathrm{P}<.01)$ and community samples $(r=.67, \mathrm{P}<.01)$. Self-criticism scores were also strongly associated across the two time points $(r=.69, \mathrm{P}<.01$, for student; and $r=.77, \mathrm{P}<.01$ for community sample). Similarly, efficacy scores were correlated with scores three weeks later for both student $(r=.81, \mathrm{P}<.01)$ and community samples $(r=.75, \mathrm{P}<.01)$.
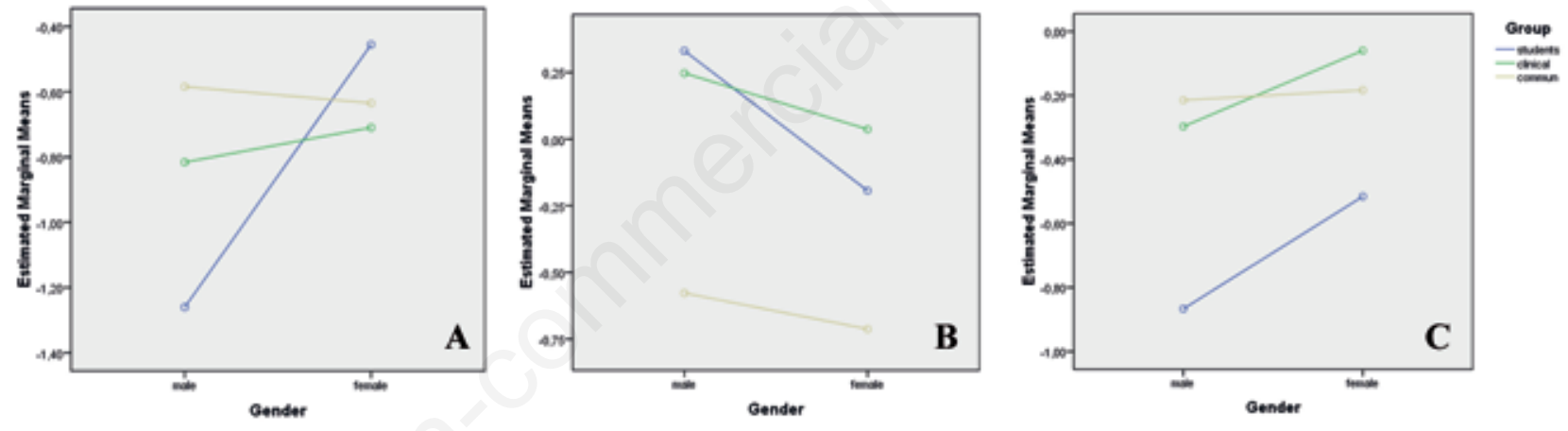

Figure 1. Interaction effect for dependency (A), efficacy (B), and self-criticism (C).

Table 2. Group and gender comparisons on the Depressive Experience Questionnaire Italian version scores.

\begin{tabular}{|c|c|c|c|c|c|c|c|}
\hline & & \multicolumn{2}{|c|}{ Overall } & \multicolumn{2}{|c|}{ Male } & \multicolumn{2}{|c|}{ Female } \\
\hline & & Mean & SD & Mean & SD & Mean & SD \\
\hline \multirow[t]{3}{*}{ Students } & Dependency & -.58 & .82 & -1.26 & .69 & -.46 & .78 \\
\hline & Self-criticism & -.11 & 1.04 & .33 & .93 & -.19 & 1.04 \\
\hline & Efficacy & -.57 & 1.00 & -.87 & .92 & -.52 & 1.01 \\
\hline \multirow[t]{3}{*}{ Clinical } & Dependency & -.74 & 1.03 & -.82 & 1.08 & -.71 & 1.02 \\
\hline & Self-criticism & .10 & 1.15 & .25 & 1.22 & .04 & 1.13 \\
\hline & Efficacy & -.13 & 1.11 & -.30 & .71 & -.06 & 1.25 \\
\hline \multirow[t]{3}{*}{ Community } & Dependency & -.62 & .80 & -.58 & .75 & -.63 & .83 \\
\hline & Self-criticism & -.66 & 1.01 & -.58 & 1.02 & -.71 & 1.01 \\
\hline & Efficacy & -.20 & 1.16 & -.21 & 1.12 & -.18 & 1.20 \\
\hline
\end{tabular}

SD, standard deviation. Means for Depressive Experiences Questionnaire factors were computed by Blatt's scoring program (Blatt et al., 1979). 


\section{Group and gender comparisons}

Results of group comparisons are shown in Table 2. Univariate ANOVA showed that there were significant effects of group status on both self-criticism $\left(F_{(2,428)}=19.06\right.$, $\mathrm{P}<.01)$ and efficacy $\left(F_{(2,428)}=5.59, \mathrm{P}<.01\right)$. Tukey's posthoc analyses revealed that individuals in the community sample showed lower scores on self-criticism than student $\left(M_{d i f f}=-0.55, \mathrm{P}<.01\right)$ and clinical $\left(M_{d i f f}=-0.76, \mathrm{P}<.01\right)$ samples, and that students showed lower scores in efficacy in comparison with clinical $\left(M_{d i f f}=-0.44, \mathrm{P}<.05\right)$ and community $\left(M_{\text {diff }}=-0.37, \mathrm{P}<.01\right)$ samples. There were no group differences on dependency scores $\left(F_{(2,428)}=0.72, \mathrm{P}=.49\right)$.

Results of gender comparisons are shown in Table 2. Female students showed higher scores in dependency than male students $\left(t_{(130)}=-4.43, \mathrm{P}<.01\right)$, whereas male students reported greater self-criticism than females $\left(t_{(130)}=2.16\right.$, $\mathrm{P}<.05)$. No significant differences between males and females were observed in the clinical group for dependency $\left(t_{(55)}=-0.36, \mathrm{P}=.72\right)$ or self-criticism $\left(t_{(235)}=0.48, \mathrm{P}=.63\right)$. Similarly, males and females did not show differences in both dependency and self-criticism scores in community sample $\left(t_{(55)}=-0.63, \mathrm{P}=.53\right.$ and $\left.t_{(235)}=1.01, \mathrm{P}=.32\right)$. Regarding efficacy, differences were not detected in any of the three samples ( $t_{s}$ ranged between -1.43 to $0.27, p_{s}>.05$ ).

A significant group $\times$ gender interaction (Figure 1) was found for dependency $\left(F_{(2,420)}=4.94, \mathrm{P}<.01\right)$, whereas there were no significant interactions of gender with either self-criticism $\quad\left(F_{(2,420)}=0.96, \quad \mathrm{P}=.39\right) \quad$ or $\quad$ efficacy $\left(F_{(2,420)}=0.63, \mathrm{P}=.36\right)$.

\section{Discussion}

The aim of this study was to examine the psychometric properties of the DEQ by contributing to its Italian validation. In line with findings obtained with other translations of the DEQ (e.g., Boucher et al., 2006; Campos et al., 2013; Kuwabara et al., 2004), results indicated acceptable psychometric properties for the Italian version of the DEQ, suggesting that dependency and self-criticism are stable, reliable, and independent personality factors that are related to depressive symptoms. When focusing on factorial analyses efficacy was independent from dependency and self-criticism and it appears to also be also a resilience factor.

However, our findings do not fully confirm Blatt's suggest view that self-criticism and efficacy factors of the DEQ refer to maladaptive and adaptive dimensions of the Self. The DEQ seems particularly evaluate the maladaptive levels of the self (self-criticism).

Consistent with prior studies (e.g., Campos et al., 2013; Luyten et al., 2007; Yao et al., 2009), our results indicate significant correlations between the two factors of the DEQ (except regarding the dependency scale for the student sample) and the BDI-II, MCMI-III, and SCL-90$\mathrm{R}$, and higher correlations with depressive symptoms in the clinical group than in the non-clinical group (students and community).

In the present study, we confirm the important role of self-criticism for psychosocial functioning. It is a global pathological trait that is strongly correlated with depressive symptoms (Blatt, 1995, 2004; Zuroff et al., 2004). It is important to underline that dependency also shows significant correlations with other scales of depression, confirming that it is correlated with interpersonal problems that can in turn contribute to depression, although it appears to be relatively less maladaptive than self-criticism.

Regarding gender differences, results suggest that dependency was higher in females, while self-criticism was higher in males both in the clinical group and in the nonclinical group (for a review, see Campos et al., 2013).

The distribution of items in our sample with factor loadings greater than .40 on the three factors was somewhat different from that reported previously by Campos et al. (2013), with 6 items (9\%) of the DEQ not having substantial loadings $(<.40)$ and 15 items $(23 \%)$ loaded strongly on more than one factor. These inconsistencies could reflect the choices made by Blatt et al. (1976) to preserve all 66 items, including items without high loadings on any of the factors and items with high loadings on more than one factor. This means that an alternative methods of scoring to those of Blatt have the effect of increasing the intercorrelation coefficients, thereby questioning the orthogonality of the two factors (Falgares, De Santis, Gullo, Scrima, Kopala-Sibley, \& Livi, 2017). According to Coyne, Thomson and Whiffen (2004), it is possible that Blatt used an orthogonal rotation to generate the factor solution upon which the original scoring procedure of the DEQ is based.

\section{Conclusions}

In sum, our findings highlighted that the Italian version showed metric qualities of the DEQ-66 similar to those previously reported (Campos et al., 2013, Desmet et al., 2007). Overall, our results confirm Blatt's hypotheses about the effectiveness of DEQ to identify characteristics of personalities prone (vulnerable) to depression in a non-clinical sample. In particular, self-criticism correlated highly $(>.30)$ with the depression scales in all three samples. Results suggest that self-criticism is indeed a depressive personality trait characterized by hostile interpersonal behavior that may be more or less pronounced in clinical as well as in non-clinical groups. In contrast, relatively weaker associations were found between dependency and depression scales in community and in student samples, whereas in the clinical sample in which these correlations were more considerable (about .30). If further confirmed by larger studies that focus on specific psychiatric disorders, results suggest dependency may be of clinical and therapeutic utility as it may permit detection of hypersensitivity or vulnerability with respect to 
specific topics of the introjective or anaclitic area.

Several limitations should be noted. First, all measures were self-report, which may have inflated associations due to shared variance. Second, the present study consisted of a relatively small clinical sample, which may limit the generalizability of our results. Third, the student sample mainly comprised female respondents that may have biased gender analyses. Finally, relations between self-criticism, dependency, efficacy, and various outcomes were examined crosssectionally; we do not know if these relationships would be found longitudinally, or if they would extend to clinical diagnoses, in addition to symptoms.

\section{References}

APA (2000). Diagnostic and Statistical Manual of Mental Disorders-Text Revised (DSM-IV-TR). $4^{\text {th }}$ ed. Washington, DC: American Psychiatric Association.

Bagby, R.M., Parker, J.D., Joffe, R.T., \& Buis, T. (1994). Reconstruction and validation of the Depressive Experiences Questionnaire. Assessment, 1, 59-68. doi:10.1177/1073 191194001001009

Beck, A.T. (1983). Cognitive therapy of depression: new perspectives. In P.J. Clayton \& J.E. Barrett (Eds.), Treatment of depression: old controversies and new approaches (pp. 265288). New York, NY: Raven Press.

Beck, A.T., Steer, R.A., \& Brown, G.K. (1996). Beck Depression Inventory (2nd ed.). San Antonio, TX: Harcourt Assessment.

Besser, A., Guez, J., \& Priel, B. (2008). The associations between self-criticism and dependency and incidental learning of interpersonal and achievement words. Personality and Individual Differences, 44, 1696-1710. doi:10.1016/j.paid. 2008.01.017

Besser, A., \& Priel, B. (2003). A multisource approach to selfcritical vulnerability to depression: The moderating role of attachment. Journal of Personality, 71, 515-556. doi:10.1111/1467-6494.7104002

Besser, A., \& Priel, B. (2005). Interpersonal relatedness and selfdefinition in late adulthood depression: personality predispositions, and protective factors. Social Behavior and Personality, 33, 351-382. doi:10.2224/sbp.2005.33.4.351

Besser, A., Priel, B., Flett, L.G., \& Wiznitzer, A. (2007). Linear and nonlinear models in vulnerability to depression: personality and postpartum depression in a high risk population. Individual Differences Research, 5(1), 1-29. Available from: http://avibesser.weebly.com/uploads/1/1/6/3/11638937/p36.pdf

Besser, A., Vliegen, N., Luyten, P., \& Blatt, S.J. (2008). Vulnerability to postpartum depression from a psychodynamic perspective: systematic empirical base commentary on issues raised by Blum (2007). Psychoanalytic Psychology, 25, 392410. doi:10.1037/0736-9735.25.2.392

Bibring, E. (1953). The mechanism of depression. In P. Greenacre (Ed.), Affective disorders: psychoanalytic contributions to their study (pp. 14-48). Oxford, UK: International Universities Press.

Blatt, S.J. (1974). Level of object representation in anaclitic and introjective depression. Psychoanalytic Study of the Child, 29, 107-157.

Blatt, S.J. (1995). Representational structures in psychopathology. In D. Cicchetti \& S. Toth (Eds.), Rochester symposium on developmental psychopathology: Vol. 6. Emotion, cognition, and representation (pp. 1-33). Rochester, NY: University of Rochester Press.
Blatt, S.J. (2004). Experiences of depression: theoretical, clinical, and research perspectives. Washington, DC: American Psychological Association.

Blatt, S.J. (2008). Polarities of experience: relatedness and self definition in personality development, psychopathology, and the therapeutic process. Washington, DC: American Psychological Association.

Blatt, S.J., \& Blass, R. (1996). Relatedness and self definition: a dialectic model of personality development. In G.G. Noam $\&$ K.W. Fischer (Eds.), Development and vulnerabilities in close relationships (pp. 309-338). Hillsdale, NJ: Lawrence Erlbaum Associates.

Blatt, S.J., D’Afflitti, J.P., \& Quinlan, D.M. (1976). Experiences of depression in normal young adults. Journal of Abnormal Psychology, 85, 383-389.

Blatt, S.J., D’Afflitti, J.P., \& Quinlan, D.M. (1979). Depressive Experiences Questionnaire. New Haven, CT: Yale University.

Blatt, S.J., Zohar, A.H., Quinlan, D.M., Zuroff, D.C., \& Mongrain, M. (1995). Subscales within the dependency factor of the depressive experiences questionnaire. Journal of Personality Assessment, 64, 319-339. doi: 10.1207/s15327752 jpa6402_11

Boucher, S., Cyr, M., \& Fortin, A. (2006). Propriétés psychométriques d'une version canadienne-française du questionnaire des expériences dépressives [Psychometric properties of a French-Canadian version of the Depressive Experiences Questionnaire]. Canadian Journal of Behavioural Sciences, 38, 230-237. doi: 10.1037/cjbs2006010

Brislin, R.W. (1970). Back-translation for cross-cultural research. Journal of Cross-Cultural Psychology, 1, 185-216. doi:10.1177/135910457000100301

Campos, C.R., Besser, A., \& Blatt, S.J. (2013). The Portuguese Version of the Depressive Experiences Questionnaire: results from a validation program in clinical and non clinical groups. Spanish Journal of Psychology, 16, 1-13. doi:10.1017/sjp.2013.104

Cohen M.B., Baker, G., Cohen, R.A., Fromm-Reichmann, F., \& Weigert, E.V. (1954). An intensive study of twelve cases of manic-depressive psychosis. Psychiatry, 17(2),103-137.

Coyne, J.C., Thompson, R., \& Whiffen, V. (2004). Is the promissory note of personality as vulnerability to depression in default? Reply to Zuroff, Mongrain, and Santor (2004). Psychological Bulletin, 130, 512-517. doi:10.1037/0033-2909. 130.3.512

Coyne, J.C., \& Whiffen, V.E. (1995). Issues in personality as diathesis for depression: the case of sociotropy-dependency and autonomy-self-criticism. Psychological Bulletin, 118, 358-378. doi: 10.1037/0033-2909.118.3.358

Derogatis, L.R. (1994). Symptom Checklist 90-R: administration, scoring, and procedures manual (3rd ed.). Minneapolis, MN: National Computer Systems, Pearson.

Desmet, M., Vanheule, S., Groenvynck, H., Verhaeghe, P., Vogel, J., \& Bogaerts, S. (2007). The Depressive Experiences Questionnaire: an inquiry into the different scoring procedures. European Journal of Psychological Assessment, 23, 89-98. doi:10.1027/1015-5759.23.2.89

Desmet, M., Vanheule, S., \& Verhaeghe, P. (2006). Dependency, self-criticism and the symptom specificity hypothesis in a sample of depressed outpatients. Social Behavior and Personality, 34, 1017-1026. doi: 10.2224/sbp.2006.34.8.1017

Desmet, M., Verhaeghe, P., Van Hoorde, H., Meganck, R., Vanheule, S., \& Murphy, C. (2009). The Depressive Experiences Questionnaire as a measure of psychoanalytic constructs reported to be measured. Psychological Reports, 105, 714720. doi: 10.2466/pr0.105.3.714-720

Falgares, G., De Santis, S., Gullo, S., Scrima, F., Kopala-Sibley, 
D.C., \& Livi, S. (2017). Psychometric aspects of the Depressive Experiences Questionnaire: implications for clinical assessment and research. Journal of Personality Assessment. doi:10.1080/00223891.2017.1282493.

Fazaa, N., \& Page, S. (2003). Dependency and self-criticism as predictors of suicidal behavior. Suicide and Life-Threatening Behavior, 33, 172-185. doi: 10.1521/suli.33.2.172.22777

Franche, R.L., \& Dobson, K. (1992). Self-criticism and interpersonal dependency as vulnerability factors to depression. Cognitive Therapy and Research, 16, 419-429. doi:10.1007/ BF01183166

Fuhr, S.K., \& Shean, G. (1992). Subtypes of depression, efficacy, and the Depressive Experiences Questionnaire. Journal of Psychology, 126, 495-506. doi:10.1080/00223980. 1992.10543383

Ghisi, M., Flebus, G.B., Montano, A., Sanavio, E., \& Sica, C. (2006). Italian adaptation from A.T. Beck, R.A. Steer, \& G.K. Brown (1996). BDI-II, Beck Depression Inventory - II. Florence: Organizzazioni Speciali.

Jacobson, E. (Ed.) (1971). Depression: Comparative studies of normal, neurotic, and psychotic conditions. New York, NY: International Universities Press.

Kinzie, J.D., \& Manson, S.M. (1987). The use of self-rating scales in cross-cultural psychiatry. Hospital \& Community Psychiatry, 38, 190-195. doi:10.1176/ps.38.2.190

Kopala-Sibley, D.C., \& Zuroff, D.C. (2014). The developmental origins of personality factors from the self-definitional and relatedness domains: a review of theory and research. Review of General Psychology, 18, 137-155. doi: 10.1037/gpr 0000013

Kopala-Sibley, D.C., Zuroff, D.C., Hankin, B., \& Abela, J.R.Z. (2015). The development of self-criticism and dependency in early adolescence and their relationship to internalizing symptoms. Personality and Social Psychology Bulletin, 41, 1094-1109. doi: 10.1177/0146167215590985

Kuwabara, H., Sakado, K., Sakado, M., Sato, T., \& Someya, T. (2004). The Japanese version of the depressive experiences questionnaire: its reliability and validity for lifetime depression in a working population. Comprehensive Psychiatry, 45, 311-315. doi: 10.1016/j.comppsych.2004.02.008

Lehman, A.K., Ellis, B., Becker, J., Rosenfarb, I., Devine, R., Khan, A., \& Reichler, R. (1997). Personality and depression: a validation study of the Depressive Experiences Questionnaire. Journal of Personality Assessment, 68, 197-210. doi: 10.1207/s15327752jpa6801_16

Luyten, P., \& Blatt, S.J. (2013). Interpersonal relatedness and self-definition in normal and disrupted personality development: retrospect and prospect. American Psychologist, 68, 172-183. doi: 10.1037/a0032243

Luyten, P., Sabbe, B., Blatt, S.J., Meganck, S., Jansen, B., De Grave, C., Maes, F., \& Corveleyn, J. (2007). Dependency and self-criticism: relationship with major depressive disorder severity of depression, and clinical presentation. Depression and Anxiety, 24, 586-596.

Millon, T., Millon, C., Davis, R., \& Grossman, S. (2006). Millon Clinical Multiaxial Inventory-III (MCMI-III) (3rd ed.). Minneapolis, MN: National Computer Systems, Pearson.

Mongrain, M., \& Zuroff, D.C. (1994). Ambivalence over emotional expression and negative life events: Mediators of depressive symptoms in dependent and self-critical individuals. Journal of Personality and Individual Differences, 16, 447-458. doi: 10.1016/0191-8869(94)90071-X

Nietzel, M.T., \& Harris, M.J. (1990). Relationship of dependency and achievement/autonomy to depression. Clinical Psychology Review, 10, 279-297. doi:10.1016/0272-7358( 90)90063-G
Ouimette, P.C., \& Klein, D.N. (1993). Convergence of psychoanalytic and cognitive-behavioral theories of depression: an empirical review and new data on Blatt's and Beck's models. In J.M. Masling \& R.F. Bornstein (Eds.), Psychoanalytic perspectives on psychopathology (pp. 191-223). Washington, DC: American Psychological Association.

Psychodynamic Diagnostic Manual Task Force (2006). Psychodynamic Diagnostic Manual. Silver Spring, MD: Alliance of Psychoanalytic Organizations.

Priel, B., \& Besser, A. (1999). Vulnerability to postpartum depressive symptomatology: Dependency, self-criticism and the moderating role of antenatal attachment. Journal of Social and Clinical Psychology, 18, 240-253. doi: 10.1521/ jscp.1999.18.2.240

Prunas, A, Sarno, I., Preti, E., Madeddu, F., \& Perugini, M. (2012). Psychometric properties of the Italian version of the SCL-90-R: a study on a large community sample. European Psychiatry, 27, 591-597. doi: 10.1016/j.eurpsy.2010.12.006

Santor, D.A., Zuroff, D.C., \& Fielding, A. (1997). Analysis and revision of the Depressive Experiences Questionnaire: examining scale performance as a function of scale length. Journal of Personality Assessment, 69, 145-163. doi: 10.1207/s15327752jpa6901_8

Santor, D.A., Zuroff, D.C., Mongrain, M., \& Fielding, A. (1997). Validating the McGill Revision of the Depressive Experiences Questionnaire. Journal of Personality Assessment, 69, 164-182. doi: 10.1207/s15327752jpa6901_9

Tabachnick, G.G., \& Fidell, L.S. (2007). Experimental Designs Using ANOVA. Belmont, CA: Duxbury.

Van de Vijver, F.J.R., \& Hambleton, R. (1996). Translating tests: some practical guidelines. European Psychologist, 1(2), 89-99.

Viglione, D.J., Clemmey, P.A., \& Camenzuli, L. (1990). The Depressive Experiences Questionnaire: a critical review. Journal of Personality Assessment, 55, 52-64. doi:10.1207/ s15327752jpa5501\&2_6

Viglione, D.J., Lovette, G.J., Gottlieb, R., \& Friedberg, R. (1995). Depressive Experiences Questionnaire: an empirical exploration of the underlying theory. Journal of Personality Assessment, 65, 91-99. doi:10.1207/s15327752jpa6501_7

Welkowitz, J., Lish, J.D., \& Bond, R.N. (1985). The Depressive Experiences Questionnaire: revision and validation. Journal of Personality Assessment, 49, 89-94. doi:10.1207/s1 5327752jpa4901_17

Yao, S., Fang, J., Zhu, X., \& Zuroff, D.C. (2009). The Depressive Experiences Questionnaire: construct validity and prediction of depressive symptoms in a sample of Chinese undergraduates. Depression and Anxiety, 26, 930-937. doi:10.1002/da.20465

Zennaro, A., Ferracuti, S., Lang, M., Roccaro, G., Roma, P., Sanavio, E., \& Horn, S.L. (2013). Diagnostic validity statistics in MCMI-III applied to an Italian sample. Applied Psychology Bulletin, 60(267), 48-57.

Zuroff, D.C., Mongrain, M., \& Santor, D.A. (2004). Conceptualizing and measuring personality vulnerability to depression: comment on Coyne and Whiffen (1995). Psychological Bulletin, 130, 489-511. doi: 10.1037/0033-2909.130.3.489

Zuroff, D.C., Quinlan, D.M., \& Blatt, S.J. (1990). Psychometric properties of the Depressive Experiences Questionnaire in a college population. Journal of Personality Assessment, 55, 65-72. doi:10.1207/s15327752jpa5501\&2_7 